\title{
Pengaruh komposisi plastik multilayer dan plastik HDPE terhadap sifat fisik papan polimer
}

\author{
Vina Lestari Riyandini ${ }^{1)^{*}}$, Wathri Fitrada ${ }^{2)}$, Hendri Sawir ${ }^{3)}$ \\ ${ }^{123}$ Sekolah Tinggi Teknologi Industri Padang, Jln. Prof. Dr. Hamka No. 121 Tabing, Padang, Indonesia \\ vinalestarird@gmail.com*
}

\begin{abstract}
ABSTRAK
Jumlah timbulan sampah plastik di laut sebesar 521,540 ton, dikarenakan belum optimlanya pengolahan sampah plastik di darat. Hal ini menjadi perhatian khusus dalam pengolahan sampah plastik. Pengolahan sampah plastik salah satunya dilakukan dengan proses daur ulang (recycle). Salah satu jenis plastik yang dikeluhkan oleh banyak pemilik bank sampah karena tidak dapat dijual ke pengepul yaitu sampah plastik multilayer. Plastik multilayer merupakan plastik dilapisan bahan aluminium foil maupun bahan lainnya (multilayer). Pada umumnya, sampah plastik multilayer hanya di daur ulang menjadi prakarya seperti tas, sandal, dompet dan lainlainl dengan tujuan memperlambat proses masuknya sampah plastik multilayer ke TPA. Oleh karena itu pada penelitian ini dilakukan proses daur ulang sampah plastik multilayer menjadi papan polimer. Dimana papan polimer ini dibuat dengan kombinasi sampah plastik HDPE sebagai matrik. Sampah plastik HDPE dan plastik multilayer dicacah, dan dicetak dan dipanaskan menggunakan hotpress. Untuk mendapatkan kualitas papan polimer yang baik perlu dilakukan penentuan komposisi yang tepat antara filler dan matrik. Penelitian ini bertujuan untuk menentukan komposisi efektif agar didapatkan kualitas papan polimer, dengan memvariasikan komposisi penyusun papan polimer dengan variasi (90\% multilayer :10\%HDPE), (50\% multilayer :50\%HDPE), (30\% multilayer :70\% HDPE) dan (10\% multilayer: 90\% HDPE). Hasil penelitian menunjukkan papan polimer dengan menunjukkan komposisi yang terbaik pada variasi 10\% Multilayer: 90\% HDPE) dengan nilai uji keteguhan patah sebesar $60 \mathrm{kgf} / \mathrm{cm}^{2}$, nilai uji kerapatan sebesar 0,94 dan nilai kadar air 0,6. Dari kualitas tersebut papan polimer yang dihasilkan belum memenuhi standar nasional indonesia untuk papan partikel. Namun papan dengan kualitas dapat digunakan sebagai bahan dasar untuk produk rumah tangga dengan kombinasi bahan lainnya.
\end{abstract}

Kata kunci:Sampah Multilayer, Papan polimer,HDPE

\begin{abstract}
The amount of plastic waste generated in the sea is 521,540 tons, because plastic waste is not managed properly on land. This is a special concern in the processing of plastic waste. One of the ways to process plastic waste is by recycling. One type of plastic that many waste bank owners complain about because they cannot be sold to collectors is multilayer plastic waste. Multilayer plastic is plastic coated with aluminum foil or other materials (multilayer). In general, multilayer plastic waste is only recycled into crafts such as bags, sandals, wallets, etc. with the aim of slowing down the process of entering multilayer plastic waste into the landfill. Therefore, in this study, the process of recycling multilayer plastic waste into polymer boards will be carried out. Where this polymer board is made with a combination of HDPE plastic waste as a matrix. HDPE plastic waste and multilayer plastic are chopped, and molded and heated using a hotpress. To get a good quality polymer board, it is necessary to determine the right composition between filler and matrix. This study aims to determine the effective composition in order to obtain the quality of the polymer board, by varying the composition of the polymer board with variations (90\% multilayer: $10 \%$ HDPE), (50\% multilayer: $50 \%$ HDPE), (30\% multilayer : 70\% HDPE) and (10\% multilayer: 90\% HDPE). The results showed that the polymer board showed the best composition in the variation of 10\% Multilayer: $90 \%$ HDPE) with a fracture toughness test value of $60 \mathrm{kgf} / \mathrm{cm} 2$, a density test value of 0.94 and a moisture content value of 0.6. From this quality, the polymer board produced does not meet the Indonesian national standard for particle board. However, quality boards can be used as a basic material for household products in combination with other materials.
\end{abstract}

Keywords: Multilayer Trash, Polymer board, HDPE 
diunggah: September 2021, direvisi: Desember 2021, diterima: Desember 2021, dipublikasi: Desember 2021

Copyright (c) 2021 Vina Lestari Riyandini, Wathri Fitrada, Hendri Sawir

This is an open access article under the CC-BY license

\section{PENDAHULUAN}

Permasalahan pengelolaan sampah di Indonesia masih menjadi perhatian khusus bagi pemerintah, terutama dalam pengolahan sampah plastik. Berdasarkan laporan salah satu media sosial, sebanyak 521,540 ton sampah plastik terdapat di laut. Hal ini menunjukkan bahwa pengolahan sampah plastik didarat belum tepat, sehingga sampah plastik beralih ke laut melalui proses alami maupun antropogenik . Dilaporkan oleh Wahyu Sudoyo (2021) timbulan sampah di Indonesia tahun 2020 sebanyak 67,8 juta ton, sampah plastik menempati posisi kedua setelah sampah organik dari sumber timbulan sampah.

Sampah plastik yang dihasilkan oleh masyarakat berjenis Polyethylene Terephthalate (PETE), High-density Polyethylene (HDPE), Polypropylene (PP) dan Polystyrene or Styrofoam (PS) dan multilayer. Saat ini pengelolaan sampah plastik telah dilakukan dengan cara mendaur ulang menjadi prakarya dan mengkonversi menjadi bahan bakar. Sampah plastik berjenis PET, HDPE, LDPE, PP, PVC dan PS berhasil didaur ulang menjadi bahan baku papan komposit, biji plastik serta prakarya lainnya dan dikonversi menjadi bahan bakar dengan metode pirolisis. Sampah plastik berjenis HDPE paling banyak didaur ulang menjadi produk dengan nilai ekonomi lebih tinggi. Seperti pada penelitian Roy Mulyono dkk (2021) memanfaatkan sampah plastic HDPE dan serbuk gergaji kayu menjadi papan komposit dengan hasil produk memiliki kualitas nilai kekuatan tarik sebesar $10 \mathrm{MPa}$ dan kekuatan impak sebesar 0.276 Joule $/ \mathrm{mm}^{2}$.

Dari berbagai jenis sampah plastik, plastik multilayer merupakan sampah yang sangat minim dilakukan pengolahan. Hal ini dikarenakan plastik multilayer memiliki lapisan penyusun yang berbeda-beda seperti silikon, besi, tembaga, mangan, seng dan aluminium. Menurut Kadir (2020) sampah plastik multilayer tidak berpotensi di daur ulang menjadi biji plastik, hal ini dikarenakan pemanasan yang berbeda pada setiap lapisan plastik dimana lapisan plastik polyetilen meleleh pada suhu $115^{\circ} \mathrm{C}$ sedangkan lapisan aluminium akan meleleh pada temperature $450^{\circ} \mathrm{C}$ (Kadir, 2012). Namun saat ini, plastik multilayer masih eksis digunakan oleh produsen sebagai pengemas produk. Hal ini dikarenakan plastik multilayer memiliki keunggulan, dimana lapisan aluminium foil memiliki kekuatan, daya tahan yang memuaskan, mampu menahan oksigen mempertahankan aroma, rasa dan warna dari sinar matahari sedangkan film plastik memiliki sifat yang tahan terhadap bahan kimia dan tahan lembab (Selpiana dkk, 2019). Komposisi sampah polimer dapat dilihat pada Tabel 1.

Tabel 1. Komposisi senyawa dalam limbah plastik berlapis aluminium foil (multilayer)

\begin{tabular}{l|ll}
\hline NO & \multicolumn{1}{l}{ KOMPONEN } & KANDUNGAN (\%) \\
\hline $\mathbf{1 .}$ & Silicon & $0,6 \%$ \\
$\mathbf{2 .}$ & Besi & $0,7 \%$ \\
$\mathbf{3 .}$ & Tembaga & $0,05-0,2 \%$ \\
$\mathbf{4 .}$ & Mangan & $1,0-1,5 \%$ \\
$\mathbf{5 .}$ & Magnesium & $0,8-1,3 \%$ \\
$\mathbf{6 .}$ & Seng & $0,1 \%$ \\
$\mathbf{7 .}$ & Aluminium & $96,7-97,4 \%$ \\
\hline
\end{tabular}

Yuriandala dkk, 2016 
Saat ini pengolahan sampah plastik multilayer hanya dilakukan daur ulang (recycle) menjadi produk prakarya sepertitas, sandal, dompet dll. Hal ini hanya memperlambat sampah multilayer untuk dibuang ke TPA. Dalam penelitian ini akan dilakukan daur ulang sampah multilayer dan sampah plastik HDPE menjadi papan komposit atau papan polimer. Papan polimer atau papan komposit merupakan papan yang dibuat dari dua material atau lebih yang digabung pada skala makro untuk membentuk material ketiga yang lebih bermanfaat (Kardiman, 2019). Menurut Salman (2018) pengembangan produk komposit memberi beberapa keuntungan, antara lain (1) mengurangi biaya bahan baku dengan memanfaatkan limbah; (2) mengembangkan produk dari pemanfaatan bahan daur ulang; (3) menghasilkan produk dengan sifat spesifik; (4) mengurangi ketergantungan pada papan atau balok dari kayu asli untuk dimanfaatkan sebagai bahan baku mebel dan produk olahan kayu lainnya.

Dalam penelitian ini digunakan bahan baku yang berasal dari limbah sampah plastik multilayer sebagai filler dan sampah plastik HDPE sebagai matrik. Untuk menghasilkan papan polimer atau papan komposit dengan kualitas sesuai dengan SNI 03-2105-2016 dibutuhkan komposisi yang tepat. Maka dalam penelitian ini dilakukan dengan memvariasi komposisi yaitu variasi A (90\% sampah plastik multilayer: $10 \%$ sampah plastik HDPE), B (50\% sampah plastik multilayer : $50 \%$ sampah plastik HDPE), C (30\% sampah plastik multilayer : $70 \%$ sampah plastic HDPE), D (10\% sampah plastik multilayer : $90 \%$ sampah plastik HDPE). Diharapkan papan komposit atau papan polimer dapat digunakan sebagai bahan baku dalam pembuatan produk rumah tangga.

\section{METODE}

Penelitian ini merupakan penelitian eksperimental. Metode penelitian eksperimental digunakan untuk membuktikan hipotesis berdasarkan hasil laboratorium. Penelitian ini bertujuan untuk mencari komposisi yang tepat dalam pembuatan papan polimer dengan parameter uji keteguhan patah, kerapatan (densitas), kadar air, dan daya serap air. Dalam penelitian ini digunakan variasi komposisi yaitu A (90\% sampah plastik multilayer: $10 \%$ sampah plastik HDPE), B (50\% sampah plastik multilayer: $50 \%$ sampah plastik HDPE), C (30\% sampah plastik multilayer: $70 \%$ sampah plastik HDPE), D (10\% sampah plastik multilayer : $90 \%$ sampah plastik HDPE).

\section{Alat dan bahan}

Adapun alat dan bahan yang digunakan dalam penelitian ini yaitu [13]: Alat (1) Timbangan digital; (2) Mesin pencacah; (3) Cetakan ukuran $30 \mathrm{~cm}$ x $30 \mathrm{~cm}$ x $1 \mathrm{~cm}$; (4) Gunting; (5) Sarung tangan (6) Hotpress. Bahan (1). Sampah plastik multilayer; (2). Sampah plastik HDPE; (4) Maleic Anhydride (MAH) sebagai compatibilizer.

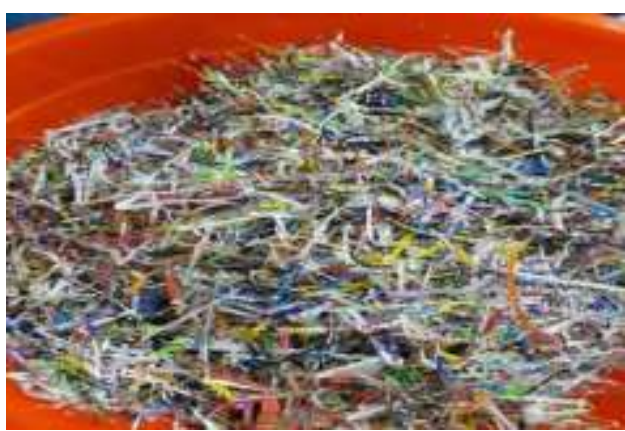

(a)

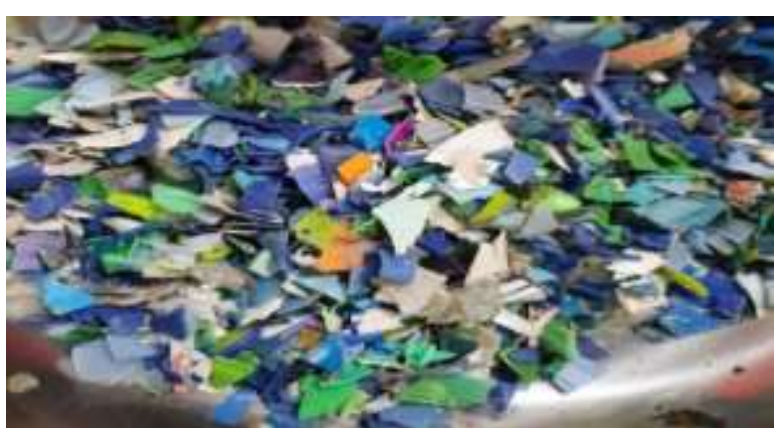

(b)

Gambar 1. (a) Sampah plastik multilayer; (b) Sampah plastik HDPE 


\section{Prosedur penelitian}

Prosedur dalam penelitian ini yaitu [13] [18], 1). Sampah plastik multilayer dan HDPE disortir dan dibersihkan; 2). Sampah multilayer dan HDPE dicacah menggunakan mesin pencacah hingga berukuran $\pm 2-5 \mathrm{~cm} ; 3$ ). Selanjutnya sampah plastik multilayer dan plastik HDPE ditimbang dengan variasi komposisi 90\% filler : $10 \%$ matrix, 50\% filler : $50 \%$ matrix, 30\% filler : $70 \%$ matrix; 3). Sampah multilayer dan HDPE yang telah ditimbang, selanjutnya dihomogenkan, lalu dimasukan ke dalam cetakan yang berukuran $30 \mathrm{~cm}$ x $30 \mathrm{~cm}$ $\mathrm{x} 1 \mathrm{~cm}$. 4) Selanjutnya ditambahkan MAH sebanyak 5\% dari berat total plastik; 5) Selanjutnya, dipanaskan menggunakan hotpress pada suhu $250^{\circ} \mathrm{C}$. 6) Selanjutnya dilakukan proses press papan polimer yang telah jadi selama 35 menit, selanjutnya papan polimer dikeluarkan dari cetakan dan didinginkan. (7) Selanjutnya dilakukan pengujian terhadap parameter Uji keteguhan patah, uji kerapatan, kadar air. (8) Percobaan yang sama dilakukan dengan variasi penambahan MAH $10 \%$.

\section{Pengolahan data}

Pengujian terhadap hasil produk yang didapatkan dengan parameter dan metode uji sebagai berikut:

Tabel 2. Parameter uji papan komposit polimer

\begin{tabular}{lll}
\hline No & Parameter & Acuan Pengujian \\
\hline 1. & Keteguhan Patah & SNI 03-2105-2006 \\
2. & Kerapatan & SNI 03-2105-2006 \\
3. & Kadar Air & SNI 03-2105-2006 \\
\hline
\end{tabular}

Selanjutnya hasil uji dibandingkan dengan karakteristik standart papan komposit berdasarkan SNI 03-2105-2006.

\section{HASIL DAN PEMBAHASAN}

\section{Kualitas papan polimer}

Kualitas fisik papan komposit atau papan polimer mengacu pada SNI 03-2105-2006 dengan kualitas fisik pada Tabel 3.

Tabel 3. Karakteristik fisik papan partikel

\begin{tabular}{clc}
\hline No & \multicolumn{1}{c}{ Parameter } & $\begin{array}{c}\text { Kualitas Papan Partikel } \\
\text { SNI 03-2105-2006 }\end{array}$ \\
\hline 1. & Keteguhan Patah (MOR) & Min $85 \mathrm{kgf} / \mathrm{cm}^{2}$ \\
2. & Kerapatan (Densitas) & $0,40 \mathrm{gr} / \mathrm{cm}^{3}-0,90 \mathrm{gr} / \mathrm{cm}^{3}$. \\
3. & Kadar Air & $<14 \%$ \\
\hline
\end{tabular}

Papan komposit atau papan partikel atau papan polimer memiliki kualitas yang baik jika memiliki nilai keteguhan patah minimal sebesar $85 \mathrm{kgf} / \mathrm{cm}^{2}$, nilai kerapatan sebesar $0,40 \mathrm{gr} / \mathrm{cm}^{3}-0,90 \mathrm{gr} / \mathrm{cm}^{3}$, kadar air sebesar $<14 \%$ dan daya serap air sebesar maksimal $25 \%$.

\section{Keteguhan patah (MOR)}

Pengujian keteguhan patah bertujuan untuk mengetahui seberapa kuat papan polimer dalam menompang beban yang ada diatasnya. Keteguhan patah (MoR) merupakan tegangan elastis yang jika diteruskan maka akan terjadi patah dan itu yang digunakan sebagai pembanding suatu material (Ega dkk, 2021). Pengujian keteguhan patah dilakukan pada papan polimer dengan variasi A (90\% Multilayer : 10\% HDPE ), B (50\% Multilayer : 50\% HDPE), C (30\% Multilayer : 70\% HDPE), D ( 10\% Multilayer : 90\% HDPE) Hasil nilai keteguhan patah dapat dilihat pada Gambar 2. 


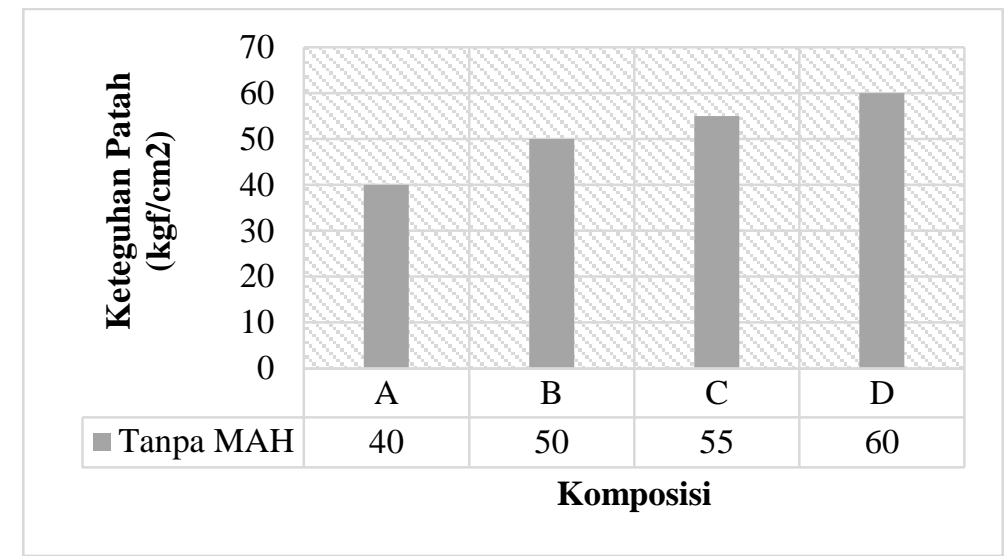

Gambar 2. Nilai keteguhan patah papan polimer

Berdasarkan hasil penelitian dengan memvariasikan komposisi bahan baku berupa sampah plastik multilayer dan sampah plastik HDPE. Variasi dengan komposisi D ( $10 \%$ Multilayer : 90\% HDPE) memiliki nilai keteguhan patah tertinggi yaitu $60 \mathrm{kgf} / \mathrm{cm}^{2}$. Sedangkan variasi A (90\% Multilayer : 10\% HDPE) memiliki nilai keteguhan patah sebesar $40 \mathrm{kgf} / \mathrm{cm}^{2}$. Gambar 2 menunjukkan semakin besar komposisi matrik menunjukkan semakin besar nilai keteguhan patah. Apabila komposisi filler ditambahkan sedangkan komposisi matriksnya berkurang, maka penambahan filler menyebabkan bertambahnya daerah yang tidak berinteraksi karena partikel-partikel dari filler tidak dapat memasuki daerah interaksi atau rongga pada papan polimer, dimana plastik HDPE yang mempunyai kemampuan mengikat kuat. Akibatnya, keteguhan patah papan polimer akan menurun.

Perekat (matrik) yang digunakan memiliki peranan penting dalam mengikat bahan pengisi (filler) pada papan polimer. Penggunaan jumlah perekat yang banyak dengan pencampuran yang merata akan menyebabkan daya ikat antar partikel yang tinggi sehingga mempengaruhi kekuatan struktural papan polimer /partikel dan menyebabkan keteguhan patah papan partikel (Suherti dkk, 2014). Sehingga peningkatan kadar perekat mampu mengikat nilai keteguhan patah (Modulus of Rupture) papan partikel atau papan polimer yang dihasilkan.

\section{Kerapatan}

Kerapatan adalah salah satu sifat fisik yang menunjukkan perbandingan antara massa benda terhadap volume yang dimilikinya atau dengan kata lain kerapatan merupakan banyaknya massa zat per satuan volume (Suherti dkk, 2014). Pengujian kerapatan dilakukan pada papan polimer dengan variasi A (90\% Multilayer : 10\% HDPE), B (50\% Multilayer : 50\% HDPE), C (30\% Multilayer : 70\% HDPE), D ( 10\% Multilayer : 90\% HDPE) Hasil nilai keteguhan patah dapat dilihat pada Gambar 3. 


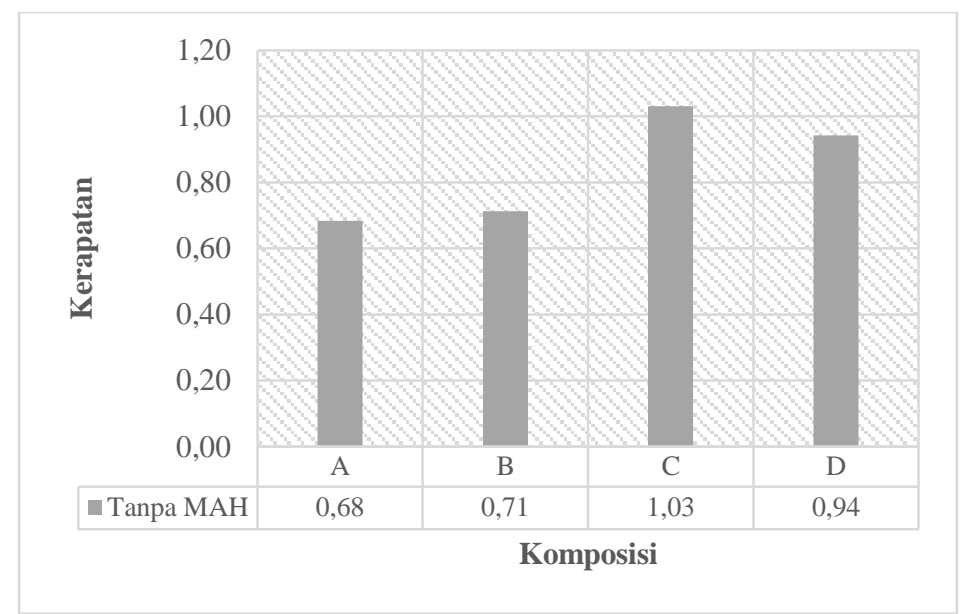

Gambar 3. Nilai kerapatan papan polimer

Mengacu pada SNI 03-2105-2006 nilai parameter kerapatan sebesar 0,4 - 0,9 gr/ $\mathrm{cm}^{3}$. Gambar 3 memperlihatkan nilai kerapatan dari hasil penelitian didapatkan nilai sebesar $0,68-1,03 \mathrm{gr} / \mathrm{cm}^{3}$. Nilai kerapan menunjukkan kemampuan bahan dalam memperkecil rongga-rongga antar partikel sehingga terjadi kerapatan. Berdasarkan hasil penelitian banyaknya jumlah matrik mempengaruhi nilai kerapatan papan komposit. Menurut Tsoumis 1991 dalam Suherti 2014 yang menyatakan bahwa papan partikel berdasarkan kerapatannya dibagi menjadi tiga yaitu papan partikel kerapatan rendah $(0.25-0.40$ $\left.\mathrm{g} / \mathrm{cm}^{3}\right)$, kerapatan medium $\left(0.40-0.80 \mathrm{~g} / \mathrm{cm}^{3}\right)$ dan kerapatan tinggi $\left(0.80-1.20 \mathrm{~g} / \mathrm{cm}^{3}\right)$. Nilai kerapatan pada penelitian ini sudah sesuai dengan nilai kerapatan pada SNI 032105-2006.

\section{Kadar air}

Pengujian kadar air pada papan polimer dilakukan dengan memvariasikan komposisi bahan baku antara sampah plastik multilayer dan sampah plastik HDPE. Pengujian kadar air dilakukan pada papan polimer dengan variasi A (90\% Multilayer: 10\% HDPE ), B (50\% Multilayer : 50\% HDPE), C (30\% Multilayer : 70\% HDPE), D ( 10\% Multilayer : 90\% HDPE) Hasil nilai kadar air pada penelitian ini dapat dilihat pada Gambar 4.

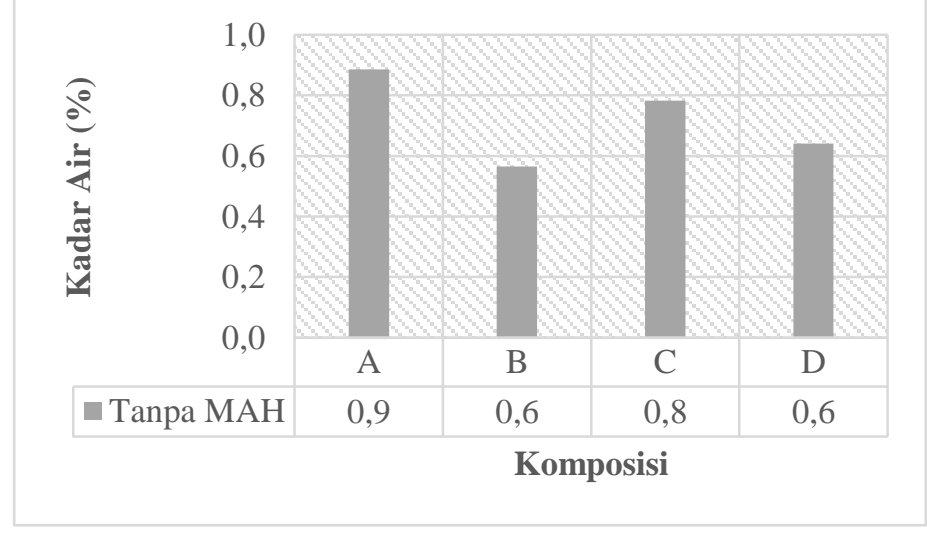

Gambar 4. Nilai kadar air papan polimer

Berdasarkan SNI 03-2105-2016 kadar air yang diperbolehkan dalam papan komposit tidak lebih dari $14 \%$. Setelah dilakukan pengujian dengan ukuran sampel $(5 \times 5 \times 1) \mathrm{cm}$ dilanjutkan pengovenan selama 6 jam dengan suhu $105^{\circ} \mathrm{C}$ didapatkan nilai kadar air dari masing-masing variasi komposisi dibawah $1 \%$. Hal ini disebabkan karena bahan baku yang digunakan terdiri dari material hidrofobik. Menurut Ida, dkk (2014) semakin tinggi 
kerapatan papan partikel, maka ikatan antar partikel akan semakin kompak dan menyebabkan rongga udara dalam lembaran papan akan semakin kecil. Keadaan tersebut akan menyebabkan air menjadi sulit untuk mengisi rongga pada papan partikel tersebut sehingga semakin kecil daya serap air papan partikel, maka stabilitas papan tersebut semakin baik, demikian pula sebaliknya.

\section{SIMPULAN}

Hasil penelitian menunjukkan komposisi yang terbaik pada variasi D (10\% Multilayer : 90\% HDPE) dengan nilai uji keteguhan patah sebesar $60 \mathrm{kgf} / \mathrm{cm}^{2}$, nilai uji kerapatan sebesar 0,94 dan nilai kadar air 0,6. Dari kualitas tersebut papan polimer yang dihasilkan belum memenuhi standar nasional indonesia untuk papan partikel. Namun papan dengan kualitas ini dapat digunakan sebagai bahan dasar untuk produk rumah tangga dengan kombinasi bahan lainnya.

\section{DAFTAR PUSTAKA}

Ida., A. Putu Wida. Wayan., K. Ngadiran., K. 2014. Pembuatan Papan Partikel dari Limbah Plastik Polyprophylene (PP) dan Tangkai Bambu. Jurnal Kimia Visvitalis (Vol 2; No 1). Universitas Pendidikan Ganesh.

Kadir. 2012. Kajian Pemanfaatan Sampah Plastik Sebagai Sumber Bahan Bakar Cair . Jurnal Ilmiah Teknik Mesin dinamika, No 2, Vol 3, ISSN :2085-8817.

Kardiman., Fauzan, D, S., Faradina, C,S., Eri, W. 2019. Pengaruh Temperatur Terhadap Sifat Mekanik pada Pembuatan Papan Komposit Berbasis Sekam Padi dan Matriks HDPE. Jurnal Ilmiah Teknik Mesin, No 1, Vol 11, E-ISSN 2502-3373.

Muhamma., E. Rosidah, dan Gusti., A. 2021. Uji Mekanika Papan Partikel Berbahan Dasar Kulit Serabut Nipah (Nyfa fruticans Wurmb) dengan Perekat Resin Polyester. Jurnal Sylva Scienteae (Vol 04 No 2). ISSN 2622-8963.

Salman, I, M., Sayoga. 2018. Papan Komposit Pengganti Papan Konvensional Untuk Meubel. Jurnal Karya Pengabdian, No 1, Vol 1; hal 6-14.

Selpiana, P., Susmanto, S., Miskah., Dharmawan., Akbar. 2012. Pemanfaatan Limbah Plastik Berlapis Aluminium (Multilayer) dengan Metode Solvasi. Jurnal Seminar Nasional Avoer XI.

Suherti, Farah Diba, Nurhaida. 2014. Sifat Fisis dan Mekanik Papan Prtikel dari Kulit Durian (Durio $S p$ ) dengan Konsentrasi Urea Formaldehid yang Berbeda. Jurnal. Universitas Tanjungpura. $\quad$ https://media.neliti.com/media/publications/10410-ID-sifat-fisik-danmekanik-papan-partikel-dari-kulit-durian-durio-sp-dengan-konsent.pdf. Diakses 10 September 2021 pukul 20.10.

Wahyu Sudoyo. 2021.Timbulan Sampah Nasional Capai 67,8 Juta Ton Pada Tahun 2020. Media Online, Info Publik. https://infopublik.id/kategori/nasional-sosialbudaya/512550/timbulan-sampah-nasional-capai-67-8-juta-ton-pada2020\#: :text=Jakarta\%2C\%20InfoPublik\%20\%2D\%20Menteri\%20Lingkungan\%20H idup,8\%20juta\%20ton\%20pada\%202020.Diakses 10 September 2021 pukul 20.30. 